\title{
Assessment of Usual Fruit, Vegetable and Vitamin C Intakes in a Sample of Egyptian Children: Pilot Study
}

\author{
Laila Hussein*, Nehad Hassan, Mahmoud Mohamad, Sahar Abdel Aziz \\ Department of Nutrition, National Research Center, Giza, Egypt \\ Email: ${ }^{*}$ dr.lailahussein@yahoo.com, nehadhassan@yahoo.com, ama1mahmoud@yahoo.com, \\ saharabdelaziz15@yahoo.com
}

Received 22 March 2015; accepted 24 July 2015; published 27 July 2015

Copyright @ 2015 by authors and Scientific Research Publishing Inc.

This work is licensed under the Creative Commons Attribution International License (CC BY). http://creativecommons.org/licenses/by/4.0/

(c) (i) Open Access

\begin{abstract}
The objective was to create an Egyptian database on the contributors of fruit and vegetables in the diets of preschool children and to estimate the usual daily intakes of fruits, vegetables and vitamin C. A total of 59 healthy boys and girls aged 2.5 - 6 years attending day care centers in urban Giza governorate completed the study by interviewing their mothers on $6 x$ non-consecutive days using the $24 \mathrm{~h}$ dietary recall. Participants were classified according to age, gender and socioeconomic class. Prevalence of daily consumptions of fruits and vegetables amounted to $22 \%$ and $54 \%$, respectively of the total children. The daily intakes of fruits and vegetables averaged $\mathbf{1 1 7 . 5}$ and $\mathbf{5 6 . 4}$ $\mathrm{g}$, respectively. The consumption of different types of fruits and vegetables was unevenly distributed by different personal and social variables. Estimated daily vitamin $C$ supply from the diet was $38 \mathrm{mg}$ per child, which satisfied the respective recommended nutrient intake (RNI) of $30 \mathrm{mg}$ for the first six years of life. However, the diet of $15 \%$ of the children covered less than $75 \%$ of RNI. Top fruits contributing to vitamin $\mathrm{C}$ were oranges, guava, watermelon, pears and grapes. Extra foods such as chipsy was consumed by $81 \%$ of the children, contributed $18 \%$ to daily vitamin $C$ supply and also $58.6 \mathrm{mg}$ sodium. A multilevel intervention strategy is warranted for promoting daily fruit and vegetable intake and healthy eating in early childhood.
\end{abstract}

\section{Keywords}

Children Aged 2.5 - 6 Years, Fruit \& Vegetable Intakes, Vitamin C Intake, Health Problems \& Vit C Deficiency

\footnotetext{
"Corresponding author.
}

How to cite this paper: Hussein, L., Hassan, N., Mohamad, M. and Aziz, S.A. (2015) Assessment of Usual Fruit, Vegetable and Vitamin C Intakes in a Sample of Egyptian Children: Pilot Study. Food and Nutrition Sciences, 6, 923-934. 


\section{Introduction}

A number of international recommendations and population targets defined the desirable level of consumption of fruit and vegetables for children [1]. Dietary guidelines convey the importance of consuming 400 grams of total fruits-vegetables at all age groups [2] and limiting salty or sweet snack foods. The daily consumption of at least one portion of fruit and one portion of vegetables was considered to be an absolute minimum in children and there is inconsistency about including or excluding potatoes, fruit juice, vegetable soup and tubers. When using 400 grams as a cut-off; $6 \%$ - 24\% of the European children 11 years old had an intake of $\geq 400$ g/day; Austrian children with $175 \mathrm{~g}$ per day were highest, while Icelander children with $80 \mathrm{~g}$ per day were the lowest [1].

Dietary vitamin C (AA) is present exclusively in fruits and vegetables and the consumption of vegetables [3] and dietary intake of vitamin $C$ has attained great importance from the point of view of prevention of disease and therapy [4]. Vitamin C is in the form of the reduced form L-ascorbic (AA) and the dike to L-dehydroascorbic acid (DHAA); both forms are biologically active to humans. The DHAA content of fresh fruits and vegetables is on the order of $5 \%-10 \%$ of total vitamin C [5] whereas storage and/or processing may increase the proportion to $30 \%$ or greater [5] [6].

The functions of A are based primarily on its properties as a reversible biologic reductant and it efficiently scavenges hydroxyl and superoxide radicals [4]. Vitamin C deficiency causes oxidative damage to lipids and proteins in the brain, which may end up with neurodegenerative diseases. Vitamin C improves the apparent iron absorption in individuals with low iron stores [7]. The antiscorbutic function of AA is attributed to hydroxylation of peptide bound proline during the biosynthesis of collagen; an important structural component of blood vessels, tendons, ligaments and bone [8].

Reactivity of radical oxygen species (ROS) with anantioxidant molecule such as vitamins C, leading to neutralised or greatly reduced reactivity [9]. After this process, the antioxidant properties of AA are lost and the vitamin must be constantly replenished or recycled.

Vitamin C accumulates in the central nervous system and the highest concentrations of ascorbate in the body are found in the brain and the neurons. Today ascorbate is proposed as a neuromodulator of glutamatergic, dopaminergic, cholinergic, and GABAergic transmission and related behaviors [10].

Vitamin C deficiency may be due to limited dietary supply or due to losses during the processing of foods as it is water soluble, easily oxidized and attacked by enzymes. The variations of ascorbic acid in fresh and thermally processing led to pronounced loss in the ascorbic acid content in all crops studied [5].

The promotion of daily fruit and vegetable consumption in childhood is important, since young children can learn to accept a greater variety of foods and flavours through repeated exposure [11] and may, to a certain extent, track into adolescence and adulthood. Food choice was thought to be influenced by a number of environmental and individual factors. Environmental factors may include food pricing [12]. Cost of food was negatively associated with dietary quality, low cost diets tending to have increased energy density and poor nutrient adequacy [13] [14].

The aim of the present study is to assess the usual intake of fruits and vegetables derived from repeated follow up dietary recalls performed among representative preschool children. The vitamin C supply with fruits and vegetables and percentage of children not satisfying the recommended vitamin $\mathrm{C}$ intake was also investigated.

\section{Materials and Methods}

\subsection{Participating Children}

Fifty nine boys and girls aged 2.5 - 6 years were recruited from four daycare- centers located in El-Haram, Giza Governorate. Data related to the age of each child was obtained from birth certificate. Mothers of the children were interviewed after the nature of the study was explained to them and the mothers gave their written consent.

Socio economic characteristic The socioeconomic status (SES) was measured by a composite score of completed educational level of the heads of the household (in years). Education has been used as a common indicator because it is easy to measure and is the most stable measure of socioeconomic status. Household income per capita (in Egyptian pounds) and parental occupation. The SES index score was predicted from the following equation [15]. Socioeconomic status $=2.259+1.016(\mathrm{C} 1)+0.886(\mathrm{C} 2)+0.622(\mathrm{C} 3)+0.013$ (C4), whereby C1 $=$ Average income of the household per month in Egyptian pounds; C2: Score of the father's occupation (score 5 - 50); C3: Score of the father's education (0 - 15 years); C4: Score of the mother's occupation. The socioeconomic levels were categorized as low with score (48 - 96); medium (97 - 144) and high (145 - 192). 


\subsubsection{Dietary Assessment}

A face-to-face six-pass 24-hour dietary recall was used to collect dietary information. Three recalls were collected during the month of December and three 24-h dietary recalls were collected during the month of August. The mothers reported the intake for their childrenand the interviews were conducted in the respondent's home. The familiar environment encouraged participation, improved the recall of foods consumed and facilitated calibration of local household utensils by the interviewer [16]. The mothers were given instructions tolist the actual amounts and forms of all foods consumed at breakfast, lunch, dinner and snacks at home and away from home during the last 24-hour dietary recalls. These included both simple foods such as fresh vegetables, fruits, juices and complex foods such as cooked recipes.

\subsubsection{Sampling Protocol}

To convert food intake into vitamin C equivalent, duplicate portions were transported to the laboratory for vitamin C determinations and 106 food items were identified. The purchase of the majority of the food cores was completed by experienced dietitians. Ready to eat dishes and commercial products such as chipsy and pickles were purchased from food stands or restaurants. At least three generous servings of each sample were collected directly from the serving lines, placed in plastic containers and packed in a portable thermo-container for transport. Dishes that required preparation or that were ingredients for mixed dishes were home-made by experienced dieticians using tradition Egyptian cooking practices approximated those used in homes.

In the laboratory, inedible portions were removed and only edible parts of vegetables and fruits were used. Portions from two to six major brands of each product were prepared for analysis.

Food description systems followed the recommended published reports [17] [18]. These included important descriptors consisting of food source, scientific name, part of the plant, major cultivars; preservation state; food processing; heat treatments; added ingredients, packaging type or storage conditions. Identifying the major commercial products was also recorded and an approximation of their sales ranking was reported.

\subsection{Laboratory Investigations}

Moisture determination The fresh edible portions were weighed, dehydrated by freeze-drying and final dry weight of each food sample was recorded and the percentage moisture was calculated.

The vitamin $\mathrm{C}$ was determined by the microfluorometric technique [19].

Food portions (0.5 - $5 \mathrm{~g}$ ) was weighed with approximate vitamin C content between 2 and $100 \mathrm{mg}$ and blended in a Waring blender with 3\% meta-phosphoric acid dissolved in $8 \%$ glacial acetic acid (mP-A-W). Juices were homogenized with mP-A-W at a ratio of 1:3 (v/v). Foodstuffs rich in basic compounds (roots; tubers and fresh leafy vegetables) were extracted with acidic solution (15 g metaphosphoric acid- $40 \mathrm{ml}$ glacial acetic and $200 \mathrm{ml}$ of diluted sulfuric acid, $0.3 \mathrm{~N}$ ) (mP-A-S). Further dilution was carried out with (mP-A-W), sothat the vitamin $\mathrm{C}$ concentration ranged between $1-5 \mathrm{mg} / 100 \mathrm{ml}$.

The $\mathrm{pH}$ was checked and adjusted to around 1.2 and the volume was brought to constant volume. After filtration, aliquots $(25 \mathrm{ml})$ were treated with norit (2 grams) for the conversion of ascorbic acid (AA) into its oxidized derivative dehydro ascorbic acid (DHAA). Aliquots of the norit treated filtrate (5 ml) were transferred into two separate $100 \mathrm{ml}$ volumetric flasks. The first flask contained $5 \mathrm{ml}$ aqueous sodium acetate solution (50\%) and the volume was completed to the mark with distilled water; whereas, the second flask contained $5 \mathrm{ml}$ boric acid (3\% dissolved in $50 \%$ sodium acetate); which converted the ascorbic acid into borate-dehydroascorbic acid complex and this served as blank. It was treated in an identical manner as the first flask. Two milliliters aliquots were taken from each flask and mixed with $0.02 \%$ aqueous ortho-phenylenediamine to form the fluorescent chinoxalin derivative. The fluorescence was measured within 30 minutes at excitation and emitting wavelengths of 350 and $430 \mathrm{~nm}$, respectively. A reagent blank was run in parallel.

Pure ascorbic acid (5 mg/dl) (Merck) was used throughout the present work as an external standard for calibration. The working solutions were prepared by dilution from the stock with (mP-A-W) to contain between 1 $50 \mu \mathrm{g}$ per ml. Aliquots were taken and treated in an identical manner as the test samples. The whole analytical process was carried out in dim light and care was given to avoid excess oxygen and temperature increase.

Quality control: A Standard Reference Material (SRM 1846) consisting of an Infant formulae was obtained from the National Institute of Standards and Technology (NIST; Gaithersburg, Maryland, USA) and was treated in a similar manner to the unknown samples. The analysis of the SRM 1846 by the present analytical method 
gave mean level of $11.3 \mathrm{mg}$ vitamin C/100g equivalent to $103.6 \%$ of the certified value (10.9 mg/100g) reported by the NIST.

Calculation: The external standard procedure was adopted throughout the course of the vitamin $\mathrm{C}$ analysis. Based on the concentration and the respective fluorescent reading of the standard ascorbic acid solutions, linear regression equation were derived and the regression factors a, b were used for calculating the ascorbic acid in the test samples.

\subsection{Estimation of the Daily Nutrient Intakes}

Six 24 hour food intake measurements for each child were the basis for estimating the usual fruits and vegetable intakes. The mean intake of the completed records was taken for each fruit and vegetable and expressed in $\mathrm{g} / \mathrm{d}$. To obtain the amount of vitamin $\mathrm{C}$ consumed, the amount of fruit or vegetable consumed in grams/d was multiplied by the vitamin $\mathrm{C}$ content in the fruit or vegetable.

The probability of adequacy was determined by dividing the dietary vitamin $\mathrm{C}$ supply by the recommended nutrient intake (RNI) of vitamin C, which is $30 \mathrm{mg}$ for the age group 2 - 6 years [20].

\section{Statistical Analysis}

The fruit and vegetable frequency questions were categorized into response category 1 - 6 and accordingly, the children were distributed according to the frequency of consumption per 6 days. Percentages, means and standard errors were calculated to describe frequency of fruit and vegetable characteristics. Mean and median estimated daily intake of fruits, vegetables and vitamin $\mathrm{C}$ among the whole study group or according to specific categories are calculated. Significant differences were assessed by using students' $t$ test or the non-parametric Chi square test. Differences with $\mathrm{P} \leq 0.05$ were considered significant.

\section{Results}

Table 1 presents number of times fruits and vegetables were reported by the children during the 6-day repeated recall period. In the total sample, $22 \%$ of the children reported to eat fruit every day, $54.2 \%$ reported to eat vegetables every day. Percentage of children who report consuming fruits less than one time daily and vegetables less than one time daily was quite high amounting to 78 and $46 \%$, respectively.

The overall daily fruit intake averaged $117.5 \pm 4.6 \mathrm{~g}$ and daily vegetable intake averaged $55 \mathrm{~g}$ (Table 2).

Table 3 presents the vitamin $\mathrm{C}$ content of selected fruits, vegetables and juices determined by the fluorometric assay. Citrus fruits and guava are the richest fruit sources in vitamin C. Paprica is the richest vegetable source in vitamin C. Chipsy is also good source of vitamin C, yet its sodium content is quite high.

The dietary supply of vitamin C averaged $38.7 \pm 2.3 \mathrm{mg}$ per day among the total participants (Table 4). The \% children with dietary vitamin C less than $75 \%$ of the RNI were $15.2 \% \%$ among the whole study group. Fruits contributed $72 \%$ of the total dietary vitamin C; juices contributed $10 \%$ of the dietary vitamin C; whereby vegetables contributed 18\%. Citrus fruits (oranges, mandarine and lemon), guava, watermelon, pear and grapes were the five top fruit contributors to vitamin $\mathrm{C}$ in the diets of the children (Figure 1). Potatoes including chipsy (6\%), tomatoes (4\%), fruiting vegetables (2.5\%) and dark green leafy vegetables (1.16\%) were the top vegetable contributors of vitamin C.

\section{Discussion}

It had been repeatedly reported that increasing the number of measurement days minimizes within-subject variation [21]. The general results on contributions of numbers of days on the accuracy of mean intake estimates showed that the benefits fall off after six days [22]. Accordingly, our study was designed using six repeated $24 \mathrm{~h}$ dietary recall on non consecutive days to assure that the released data represents usual food intakes.

The daily consumption of at least one portion of fruit and one portion of vegetables has been considered a minimum in children [1]. A survey carried out on nine European countries reported that $43.2 \%$ of the 11 -yearold children ate fruit every day; whereas, $46 \%$ ate vegetables every day [23]. Percent Australian children 2 - 16 years consuming fruits and vegetables every day amounted to $69.3 \%$ and $69.1 \%$, respectively [24]. In Brazil, $66.2 \%$ and $48.6 \%$ of the adolescents consumed fruits and vegetables every day [25]. 
Table 1. Distribution of the children according to frequency of fruits and vegetables intake per 6 days.

\begin{tabular}{|c|c|c|c|c|c|c|c|c|}
\hline \multirow[t]{2}{*}{ Category } & \multirow[b]{2}{*}{ Number } & \multirow[b]{2}{*}{ Age, mo } & \multicolumn{6}{|c|}{ Frequency fruit intakes per 6 days } \\
\hline & & & Day 1 & Day 2 & Day 3 & Day 4 & Day 5 & Day 6 \\
\hline \multicolumn{9}{|c|}{ Fruits } \\
\hline All children & 59 & $54.2 \pm 1.5$ & & 10.2 & 23.7 & 23.7 & 20.3 & 22.0 \\
\hline Age group $<4$ years & 13 & $37.7 \pm 1.3$ & & 23.1 & 38.5 & 23.1 & 15.4 & 0.0 \\
\hline Age group $\geq 4$ years & 46 & $58.8 \pm 1.2$ & & 6.5 & 19.6 & 23.9 & 21.7 & 28.3 \\
\hline Boys & 34 & $54 \pm 1.9$ & & 2.9 & 26.5 & 20.6 & 26.5 & 23.5 \\
\hline Girls & 25 & $54.4 \pm 2.5$ & & 20 & 20 & 28 & 12 & 20 \\
\hline SES (1) & 15 & $61.8 \pm 2.4$ & & 13.3 & 13.3 & 40.0 & 13.3 & 20.0 \\
\hline SES (2) & 21 & $52.9 \pm 2.5$ & & 14.3 & 19.0 & 14.3 & 38.1 & 14.3 \\
\hline SES (3) & 23 & $51.2 \pm 2.5$ & & 4.3 & 34.8 & 21.7 & 8.7 & 30.4 \\
\hline \multicolumn{9}{|c|}{ Vegetables } \\
\hline All children & 59 & $54.2 \pm 1.5$ & 1.7 & 1.7 & 0.0 & 11.9 & 30.5 & 54.2 \\
\hline Age group $<4$ years & 13 & $37.7 \pm 1.3$ & & 7.7 & 0.0 & 23.1 & 38.5 & 30.8 \\
\hline Age group $\geq 4$ years & 46 & $58.8 \pm 1.2$ & 2.2 & 0.0 & 0.0 & 8.7 & 28.3 & 60.9 \\
\hline Boys & 34 & $54 \pm 1.9$ & 0.0 & 0.0 & 0.0 & 8.8 & 35.3 & 55.9 \\
\hline Girls & 25 & $54.4 \pm 2.5$ & 4.0 & 4.0 & 0.0 & 16.0 & 24.0 & 52.0 \\
\hline SES (1) & 15 & $61.8 \pm 2.4$ & 6.7 & 0.0 & 0.0 & 26.7 & 13.3 & 53.3 \\
\hline SES (2) & 21 & $52.9 \pm 2.5$ & & & & 4.8 & 38.1 & 52.4 \\
\hline SES (3) & 23 & $51.2 \pm 2.5$ & 0.0 & 4.3 & 0.0 & 8.7 & 34.8 & 52.2 \\
\hline
\end{tabular}

Table 2. Distribution of the children according to daily fruit and vegetables intake in grams.

\begin{tabular}{|c|c|c|}
\hline \multirow{2}{*}{ Category } & Estimated & Median \\
\hline & Average $(\mathrm{X} \pm \mathrm{SE})$ & $(g / d)$ \\
\hline \multicolumn{3}{|c|}{ Fruit } \\
\hline All children & $117.5 \pm 4.6$ & 113 \\
\hline Age group $<48 \mathrm{mo}$ & $109.1 \pm 11.2$ & 93 \\
\hline Age group $\geq 48 \mathrm{mo}$ & $119.9 \pm 5.0$ & 120 \\
\hline Boys & $130.7 \pm 6.6$ & 135.5 \\
\hline Girls & $107.8 \pm 5.8$ & 98 \\
\hline SES, Low & $130.6 \pm 9.5$ & 131 \\
\hline SES, Medium & $111.6 \pm 6.1$ & 96.5 \\
\hline SES, High & $114.4 \pm 8.2$ & 117.2 \\
\hline \multicolumn{3}{|c|}{ Vegetables } \\
\hline All children & $56.4 \pm 2.3$ & 55.9 \\
\hline Age group $<48 \mathrm{mo}$ & $55.4 \pm 6.2$ & 50.7 \\
\hline Age group $\geq 48 \mathrm{mo}$ & $56.6 \pm 2.4$ & 55.9 \\
\hline Boys & $57 \pm 3.2$ & 54.9 \\
\hline Girls & $55.5 \pm 3.4$ & 56.8 \\
\hline SES, Low & $62.6 \pm 4.3$ & 66.8 \\
\hline SES, Medium & $57.0 \pm 4.0$ & 54.3 \\
\hline SES, High & $51.6 \pm 2.6$ & 50.7 \\
\hline
\end{tabular}


Table 3. Mean vitamin C and moisture contents in fruits and vegetables commonly consumed in Egypt.

\begin{tabular}{|c|c|c|c|c|c|c|}
\hline Item & Eaten & Edible & Processing & Moisture & Energy & Vitamin C \\
\hline & & proportion & & $\%$ as eaten & Kcal/100g & $\mathrm{mg} / 100 \mathrm{~g}$ \\
\hline Cabbage & Leaves & 0.71 & Boiled & 92.8459 & & 5.76 \\
\hline Carrots & Root & 0.86 & Raw & 92.1 & 28.1 & 4.87 \\
\hline Carrots & Root & 0.82 & Boiled & 92.5 & 28.3 & 2.99 \\
\hline Carrots & Root & 1 & Pickles & 90.4 & 29.3 & 1.8 \\
\hline Cauliflower & Flower & 0.75 & Boiled & 94.3 & 20.5 & 9.32 \\
\hline Cauliflower & Flower & 0.75 & Recipe & 86.7 & 55.0 & 7.9 \\
\hline Cauliflower & Flower & 0.78 & Fried & 68.7 & 181.2 & 12.64 \\
\hline Cauliflower & Leaves & & Fried, w eggs & 59.7 & 199.2 & 6.75 \\
\hline Celery & Leaves & 0.64 & Raw & 93.2 & 7.0 & 5.13 \\
\hline Coriander & Leaves & 0.46 & Raw & 91.5 & & 116.6 \\
\hline Cucumber & Fruit & 0.87 & Raw & 96.1 & 12.9 & 22 \\
\hline Dill & Leaves & 0.7 & Raw & & & 48.98 \\
\hline Eggplant purple color & Fruit & 0.84 & Boiled & 93.9 & 23.8 & 3.12 \\
\hline Eggplant white colour & Fruit & 0.88 & Boiled & 93.6 & 23.8 & 1.1 \\
\hline Eggplant white colour & Fruit & 0.88 & Pickles & 76.7 & 89.5 & 1.48 \\
\hline Eggplants & Fruit & 0.88 & Fried & 76.2 & 159.2 & 16.2 \\
\hline Eggplants & Fruit & 0.88 & Fried, pickled & 79.2 & 76.1 & 2.235 \\
\hline Eggplants & Fruit & 0.8 & Recipe & 69.5 & 179.7 & 28.37 \\
\hline Garden rocket & Leaves & 0.55 & Raw & 92.7 & 21.2 & 98.12 \\
\hline Garlic & Fruit & 0.22 & Raw & 69.4 & & 3.97 \\
\hline Grape leaves & Leaves & 0.82 & Raw & 74.7 & 108.4 & 76.2 \\
\hline Grape leaves & Leaves & 0.83 & Recipe w rice & 87.1 & 55.4 & 13.58 \\
\hline Green beans & Pods & 0.73 & Recipe & 89.1 & 144.6 & 5.7 \\
\hline Jews mallow & Leaves & 1 & $\begin{array}{c}\text { Raw, Sun } \\
\text { dehydration, ground }\end{array}$ & 9.5 & 342.9 & 14.5 \\
\hline Jews mallow & Leaves & 0.25 & Recipe & 92.1 & 29.8 & 1.68 \\
\hline Leeks & Leaves & 0.87 & Raw & 93.2 & & 18.26 \\
\hline Lemon & Fruit & 0.56 & Pickles & 83.1 & 69.5 & 5.76 \\
\hline Salad & Green & 0.8 & Raw & 93.4 & & 8.97 \\
\hline Green mallow & Leaves & 0.8 & Boiled & 90.4 & 38.7 & 6.92 \\
\hline Green mallow & Leaves & 0.8 & Recipe & 81.8 & 80.7 & 1.49 \\
\hline Okra & Fruit & 0.88 & $\begin{array}{c}\text { Raw, Sun } \\
\text { dehydration, ground }\end{array}$ & 51.0 & 176.0 & 24.03 \\
\hline Okra & Fruit & 0.8 & Recipe & 87.1 & 52.8 & 9.94 \\
\hline Okra & Fruit & 0.8 & Recipe w tomato & 83.9 & 79.9 & 8.9 \\
\hline Onion & White Bulb-leaves & & Raw & 90.2 & 34.7 & 4.2 \\
\hline Onion & White Bulb-leaves & & Boiled & 85.7 & 51.9 & 7.74 \\
\hline Onion & Red Bulb-leaves & & Raw & 87.8 & 43.7 & 3.65 \\
\hline Parsley & Leaves & 0.62 & Raw & 85.7 & 48.6 & 114.2 \\
\hline
\end{tabular}




\section{Continued}

\begin{tabular}{|c|c|c|c|c|c|c|}
\hline Parsley & Leaves & 0.62 & Boiled & 92.4 & 26.8 & 53.2 \\
\hline Peas & Seeds & 0.48 & Boiled & 76.2 & 90.8 & 4.77 \\
\hline Peas & Seeds & 0.5 & $\begin{array}{c}\text { Recipe w } \\
\text { carrots-tomato }\end{array}$ & 80.2 & 91.9 & 3.1 \\
\hline Peas & Seds & 0.5 & Recipe w tomato & 81.0 & 72.3 & 4.2 \\
\hline Pepper bell green & Fruit & 0.82 & Raw & 92.6 & 26.5 & 68 \\
\hline Pepper hot green & Fruit & 0.97 & Raw & 91.7 & 30.4 & 75.9 \\
\hline Pepper hot green & Fruit & 0.95 & Boiled & 92.1 & 30.1 & 47 \\
\hline Pepper bell green & Fruit & 0.8 & Boiled & 88.6 & 60.3 & 152.9 \\
\hline Pepper bell green & Fruit & 0.82 & Recipe, w rice fillings & 75.3 & & 44.4 \\
\hline Pepper hot & Fruit & & Pickles & 84.5 & 70.7 & 18.13 \\
\hline Potato & Tuber & 1 & Boiled ;peeled & 81.5 & 67.1 & 18.9 \\
\hline Potato & Tuber & 0.81 & Boiled w peel & 79.2 & 76.9 & 9.95 \\
\hline Potato & Tuber & 0.81 & Stewed; oil added & 73.8 & 126.2 & 13.8 \\
\hline Potato & Portion & 0.81 & Pommes frittes & 24.4 & 28.8 & 7.8 \\
\hline Potato & Serving dish & 0.83 & Cooked w tomato & 78.2 & 76.9 & 7.3 \\
\hline Raddish & Root-Leaves & 0.59 & Raw & 91.9 & 35.7 & 64.1 \\
\hline Spinach & Leaves & 0.45 & Boiled & 87.4 & 40.9 & 8.2 \\
\hline Spinach & Serving dish & 0.5 & Cooked w tomato & 87.0 & 60.8 & 7.3 \\
\hline Squash & Fruit & 0.83 & Boiled & 89.1 & 34.2 & 5.6 \\
\hline Squash & Serving dish & & Cooked w tomato & 87.2 & 40.4 & 5.3 \\
\hline Sweet potato & Tuber & 0.9 & Boiled & 71.8 & 270.6 & 10.54 \\
\hline Sweet potato & Tuber & 0.9 & Baked & 71.7 & 269.1 & 34.05 \\
\hline Taro & Tuber & 0.84 & Boiled & 80.9 & 64.6 & 4.1 \\
\hline Taro & Serving dish & & Recipe w tomato & 80.7 & 82.5 & 4.1 \\
\hline Taro & Serving dish & 0.8 & Recipe w celery & 82.0 & 63.6 & 5.2 \\
\hline Tomatoes & Fruit & & Raw & 83.9 & 84.1 & 18.6 \\
\hline Tomatoes & Fruit & 0.98 & Boiled & 93.8 & 23.3 & 10.7 \\
\hline Tomatoes & Fruit & & Tomato salad & 77.4 & 72.7 & 6.47 \\
\hline Carrots & Mixed & 1 & Pickles & 87.6 & 21.5 & 0.8 \\
\hline White beans & Seeds & 1 & Boiled & 60.5 & 152.7 & 2.875 \\
\hline White beans & & 1 & Recipe w tomato & 72.0 & 113.5 & 3.3 \\
\hline \multicolumn{7}{|l|}{ Fruits } \\
\hline Apple & Fruit & 0.9 & Raw local & 87.0 & 48.0 & 3.2 \\
\hline Apple American golden & Fruit & 0.94 & Raw imported & 85.1 & 55.2 & 5.58 \\
\hline Apple American red & Fruit & 0.93 & Raw imported & 86.1 & 51.2 & 3.9 \\
\hline Apple Syrian golden & Fruit & 0.92 & Raw imported & 82.7 & 64.2 & 3.2 \\
\hline Pommegranate & Fruit & 0.5 & Raw local & 80.4 & 72.8 & 11.54 \\
\hline Apricots & Fruit & 0.93 & Raw local & 85.9 & 50.2 & 7.8 \\
\hline Banana & Fruit & 0.7 & Raw local & 84.7 & 55.0 & 5.65 \\
\hline
\end{tabular}




\section{Continued}

\begin{tabular}{|c|c|c|c|c|c|c|}
\hline Banana & Fruit & 0.75 & Raw, imported & 81.7 & 66.7 & 6.78 \\
\hline Cantalope & Fruit & 0.61 & Raw & 91.9 & 28.2 & 29.9 \\
\hline Dates dehydrated & Fruit & 0.85 & Raw, dehydrated & 45.4 & 199.0 & 7.18 \\
\hline Dates Zaghloul red & Fruit & 0.85 & Raw, fresh & 62.6 & 136.5 & 8.62 \\
\hline Dates Samaniyellow & Fruit & & Raw, fresh & 60.7 & 147.3 & 5.79 \\
\hline Figs & Fruit & 0.9 & Raw, fresh & 82.2 & 66.1 & 10.9 \\
\hline Grapes purple & Fruit & 0.98 & Raw, local & 84.7 & 55.2 & 4.2 \\
\hline Grapes seedless & Fruit & 0.95 & Raw, local & 82.8 & 62.0 & 4.06 \\
\hline Grape fruits & Fruit & 0.88 & Raw, local & 90.1 & 35.4 & 45.4 \\
\hline Guave & Fruit & 0.97 & Raw, local & 86.8 & 50.1 & 102.3 \\
\hline Mandarine & Fruit & 0.75 & Raw, local & 86.9 & 48.3 & 39.9 \\
\hline Mango & Fruit & 0.51 & Raw, local & 83.9 & 60.0 & 32.9 \\
\hline Melon & Fruit & 0.8 & Raw, local & 93.4 & 22.8 & 20.2 \\
\hline Mulberry & Fruit & 0.98 & Raw, local & 83.2 & 64.6 & 17.49 \\
\hline Mulberry purple & Fruit & 0.97 & Raw, local & 84.9 & 56.8 & 21.49 \\
\hline Oranges baladi & Fruit & 0.77 & Raw, local & 86.4 & 50.7 & 53.16 \\
\hline Oranges besorra & Fruit & 0.75 & Raw, local & 86.0 & 52.9 & 49.95 \\
\hline Oranges sokkari & Fruit & 0.74 & Raw, local & 87.4 & 47.8 & 48.2 \\
\hline Oranges summer & Fruit & 0.81 & Raw, local & 86.8 & 49.9 & 44.2 \\
\hline Peaches & Fruit & 0.8 & Raw, local & 85.6 & 53.6 & 9.38 \\
\hline Pears & Fruit & 0.96 & Raw, local & 84.8 & 57.1 & 17.81 \\
\hline Plums golden & Fruit & 0.88 & Raw, local & 84.2 & 58.3 & 5.05 \\
\hline Prickly pear & Fruit & 0.85 & Raw, local & 85.0 & 54.1 & 13.12 \\
\hline Water melon & Fruit & 0.56 & Raw, local & 90.7 & 33.7 & 7.9 \\
\hline \multicolumn{7}{|l|}{ Juices } \\
\hline Carrots & Juice & 1 & Proc, local & 93.0 & 29.8 & 3.39 \\
\hline Cocktail & Juice & 1 & Proc, local & 81.4 & 73.5 & 15.47 \\
\hline Guava & Juice & 1 & Proc, local & 84.9 & 33.0 & 32.6 \\
\hline Mango & Juice & 1 & Proc, local & 81.3 & 72.6 & 5 \\
\hline Milk-banana & Beverage & 1 & Fresh & 76.3 & 90.5 & 2 \\
\hline Milk-mango & Beverage & 1 & Fresh & 80.6 & 81.2 & 0.14 \\
\hline Milk-strawberries & Beverage & 1 & Fresh & 80.8 & 81.4 & 6.51 \\
\hline Orange & Juice & 1 & Proc, local & 91.3 & 32.5 & 35.37 \\
\hline Orange carrots & Juice & 1 & Proc, local & 90.0 & 37.0 & 29.7 \\
\hline Orange peaches & Juice & 1 & Proc, local & 85.9 & 53.2 & 22.2 \\
\hline Pine apple & Beverage & 1 & Proc, local & 86.6 & 50.6 & 11.31 \\
\hline Straw berry & Beverage & 1 & Proc, local & 80.4 & 60.7 & 28.5 \\
\hline
\end{tabular}


Table 4. Mean and median dietary vitamin C supply and \% children below the recommended nutrient intake.

\begin{tabular}{|c|c|c|c|c|}
\hline & \multicolumn{2}{|c|}{ Dietary vit C supply, mg } & \multirow{2}{*}{$\%$ children $<75 \% \mathrm{RNI}^{*}$} & \multirow{2}{*}{ Chi square tes } \\
\hline & $($ Mean $\pm \mathrm{SE})$ & Median & & \\
\hline All children & $38.7 \pm 2.3$ & 35.5 & 15.25 & \\
\hline Age group $<48 \mathrm{mo}$ & $34.2 \pm 4.4$ & 29.1 & 18.18 & \\
\hline Age group $\geq 48 \mathrm{mo}$ & $40.8 \pm 2.7$ & 41 & 15.2 & \\
\hline Boys & $41.8 \pm 3.1$ & 39.5 & 8.8 & \\
\hline Girls & $34.5 \pm 3.4$ & 33.1 & 24 & $2.57^{\#}$ \\
\hline SES, Low & $35.9 \pm 3.9$ & 40.4 & 26.7 & 2.03 \\
\hline SES, Medium & $38.7 \pm 3.5$ & 30.8 & 9.5 & \\
\hline SES, High & $40.6 \pm 4.5$ & 35.5 & 13 & \\
\hline
\end{tabular}

"The age groups 2.5 - 6 years; ${ }^{*} \mathrm{P}<0.05$.
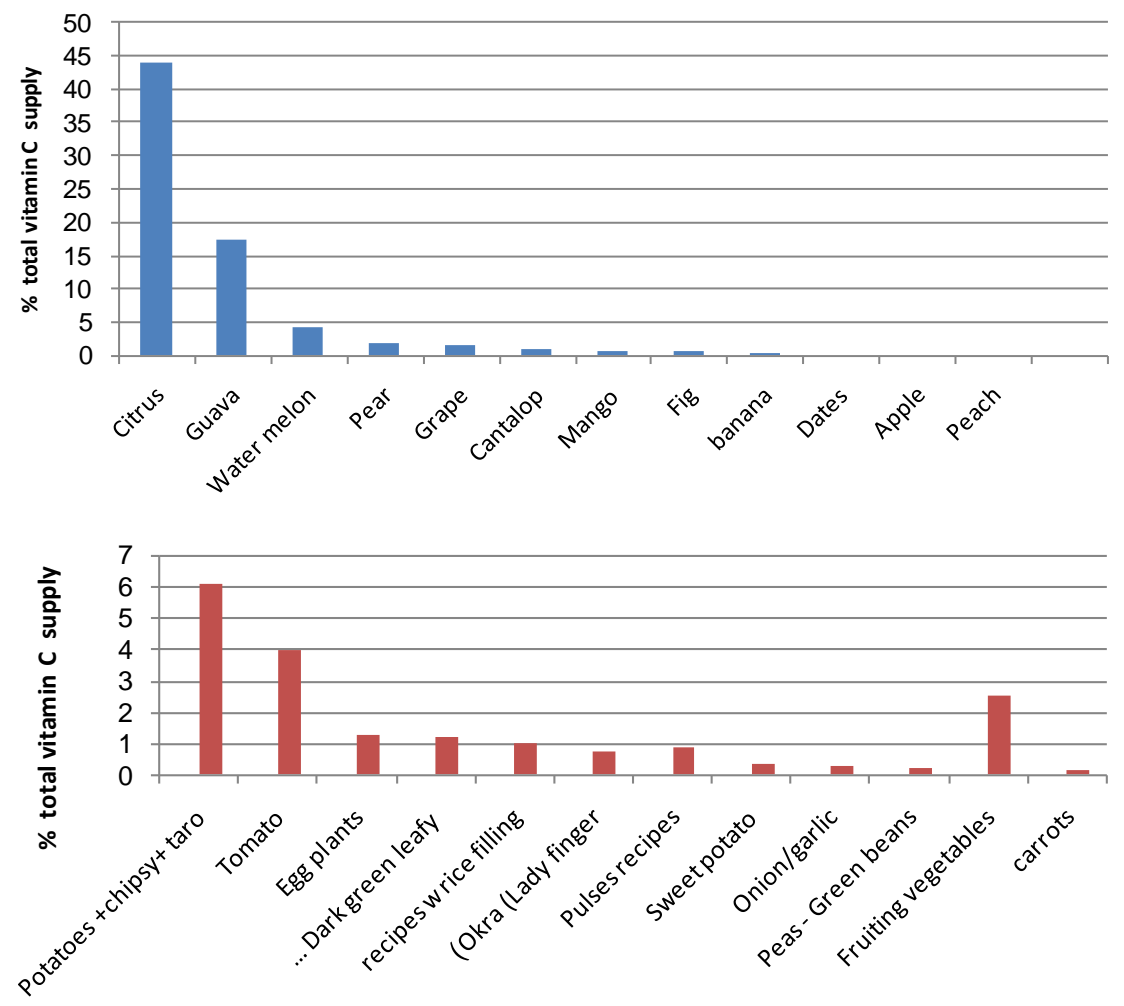

Figure 1. Legend to figures \% total vitamin C supply.

In the present study, $54 \%$ of the children ate vegetables every day, which is overlapping with the above mentioned reports. However, only $22 \%$ of the children ate fruits every day, which is far below the guideline of daily fruit consumption. In agreement with earlier reports, the consumption of different types of fruits and vegetables was unevenly distributed by different personal and social variables [26].

The median vegetable consumption decreased from 64.6, to 55.5 to $45.6 \mathrm{~g}$ among children from households with low, medium and high socioeconomic class, respectively.

Estimated fruit supply in the diet of our children 2.5 - 6 years is 58\% the respective intakes of figures of Australian children. Estimated total fruit intakes of 179 and 177 gram had been reported for Australian children in the age groups 2 - 3 and 4 - 8, respectively [24]. 
The dietary fruit and vegetable supplies in the diet of our children is still better than those reported for Indian children. Mean daily intakes of 26, 35, 12.5 and 14.6 grams fruits were reported for boys and girls (2 - 4 years) and (4 - 6 years) respectively. Respective mean daily intakes of vegetables were 64.0, 59.91, 71.28, 71.92, 12.46, $14.5671 .3,59.1$ and 55.7 and 71.92 [27]. The authors considered these amounts significantly low and wouldn’t satisfy the RNI.

In the United Kingdom, a survey reported mean daily fruit intake of $148 \mathrm{~g} / \mathrm{d}$ for children 8 years of age in families never eating meal together at a table, which increased to 229 in families always eating together. The respective vegetable supply was 66 and $113 \mathrm{~g} / \mathrm{d}$ [28].

The vitamin [C] composition data of new forms of vegetables and fruits appearing in the market and the important commercially prepared foods are generally unavailable. The formulations of such food commodities are nonexistent and are frequently different from home-prepared products so that their vitamin [C] composition should be determined by analysis [6]. Food analysis is costly and laborious, analytical data are frequently borrowed from tables of developed countries and incorporated in tables of developing countries.

For the generation of accurate analytical food composition table vitamin $\mathrm{C}$ was analyzed based on nationally based sampling and actual chemical analyses for foods. We took advantage of this table to gain an insight into the adequacy of this practice by estimating the vitamin $\mathrm{C}$ content in the diets of Egyptian preschool children

Dietary supply of vitamin $\mathrm{C}$ among children from European and American populations is much superior compared to those estimated in the present study and in reports for African and Asian children.

Dietary intake surveys estimate US per capita vitamin C intakes at approximately $83 \mathrm{mg} /$ day for children age 1 to 5 years [29]. Approximately 90\% of the vitamin C comes from fruits and vegetables, with citrus fruits being main contributors [6]. Furthermore, high mean intakes of vitamin C equivalent to 202 and 166\% of the Recommended Dietary Allowances were reported for children from food sufficient and insufficient households, respectively [30]. Dietary vitamin C supply averaged 90.5 and 53.5 mg for American and Russian children, respectively [31]. Respective mean, median estimated vitamin C intakes of 30.6 and $24 \mathrm{mg} /$ day and $80 \%$ prevalence of adequacy were reported among children from Bangladesh 2 - 4 years [32]. The authors attributed the low intakes primarily due to low diversity of foods. In South Africa, estimated vitamin C intakes of 29 and $52 \mathrm{mg} /$ day were reported for children 2 - 5 years of age, when the $24 \mathrm{~d}$ recall was conducted during the months of February and November, respectively [33].

In rural Zambia, the roots and tubers contributed to the intake of vitamin $\mathrm{C}$ by $16 \%$ in the diet of Zambian children two years of age; while respective contribution of fruits and vegetables amounted to 28\% [34]. In the present study, tubers and potatoes were also the top vegetable contributors to vitamin dietary vitamin C supply. Chipsy and fried potatoes were consumed by $81 \%$ of the children with weighted daily intake of 8.4 g contributing $3.2 \%$ of the daily vitamin C supply.

Unfortunately, the consumption of chipsy was associated with $50 \mathrm{mg}$ increase in the daily intake of sodium. Respective amounts of chipsy and fried potatoes consumed by Australian children 2 - 3 and 4 - 8 years were 32 and 47 grams, respectively [24]. In the US, chips, crackers, popcorn and pretzels consumed by children 2 - 18 years contributed higher daily sodium intake of $192.6 \mathrm{mg}$ [29]. Childhood is a sensitive period with respect to effects of sodium on future blood pressure [35]. The majority of children exceeded recommendation levels of sodium intake at 2 - 6 years and interventions to reduce sodium in childhood should be considered.

Vitamin $\mathrm{C}$ is the important single nutritional factor viewed as essential for healthy life across the lifespan. Its deficiency probably increases morbidity and mortality in children, emphasizing the public health importance of this disorder. Some sources now suggest that recommended dietary allowance (RDA) of vitamin C should be as much as double the currently advised per day depending on age and gender [36].

Results obtained from the present survey serves as baseline measurement to track consumption of fruits and vegetables over time to monitor progress towards increased F\&V consumption, a key recommendation of the Dietary Guidelines for World Health organization.

Promoting healthier eating patterns among children is crucial for optimal growth and development. Because children's eating patterns are influenced by such a range of characteristics of the social and physical environment, it is important to develop interventions that target the different levels at which these influences occur.

Busy families rely on convenient foods which often come from fast food establishments, other restaurants, and the pre-packaged food sections of the grocery store [37]. Hurried families no longer have time to sit down to eat meals together, even though eating together has been associated with greater intake of foods from the basic food groups contributing to less than optimal eating patterns [28]. There is still more work to be done to promote 
healthier eating patterns using a multi-faceted approach targeting children, parents, families and schools. Attempting to increase F\&V consumption should include strategies to improve access and establish policies that make it easier to target child care centers, as children are spending more of their time in these settings. These interventions could focus on making fruit and vegetables as healthful food choices. The state can support increased fruit and vegetable consumption by ensuring that their child care regulations closely align with national standards for serving fruits and vegetables.

\section{Acknowledgements}

The study was supported by the Food and Agriculture Organization (TCP/EGY/6714). Thanks are extended to all children and mothers participated in the survey.

\section{References}

[1] Yngve, A., Wolf, A., Poortvliet, E., Elmadfa, I., Brug, J., Ehrenblad, B., et al. (2005) Fruit and Vegetable Intake in a Sample of 11-Year-Old Children in 9 European Countries: The Pro Children Cross-Sectional Survey. Annals of Nutrition \& Metabolism, 49, 236-245. http://dx.doi.org/10.1159/000087247

[2] WHO (2008-2013) Action Plan for the Global Strategy for the Prevention and Control of Noncommunicable Diseases. World Health Organization, Geneva.

[3] Agudo, A., Slimani, N., Ocke, M.C., et al. (2002) Consumption of Vegetables, Fruit and Other Plant Foods in the European Prospective Investigation into Cancer and Nutrition (EPIC) Cohorts from 10 European Countries. Public Health Nutrition, 5, 1179-1196. http://dx.doi.org/10.1079/PHN2002398

[4] Domitrović, R. (2006) Vitamin C in Disease Prevention and Therapy. Biochemia Medica, 16, 107-125.

[5] Lee, S.K. and Kader, A.A. (2000) Preharvest and Postharvest Factors Influencing Vitamin C Content of Horticultural Crops. Postharvest Biology and Technology, 20, 207-220. http://dx.doi.org/10.1016/S0925-5214(00)00133-2

[6] Sinha, R., Block, G. and Taylor, P.R. (1993) Problems with Estimating Vitamin C Intakes. The American Journal of Clinical Nutrition, 57, 547-550.

[7] Hunt, J.R., Gallagher, S.K. and Johnson, L.A.K. (1994) Effect of Ascorbic Acid on Apparent Iron Absorption by Women with Low Iron Stores. The American Journal of Clinical Nutrition, 59, 1381-1385.

[8] England, S. and Seifter, S. (1986) The Biochemical Functions of Ascorbic Acid. Annual Review of Nutrition, 6, 365406. http://dx.doi.org/10.1146/annurev.nu.06.070186.002053

[9] Buettner, G.R. (1993) The Pecking Order of Free Radicals and Antioxidants: Lipid Peroxidation, Alpha-Tocopherol, and Ascorbate. Archives of Biochemistry and Biophysics, 300, 535-543. http://dx.doi.org/10.1006/abbi.1993.1074

[10] Harrison, F.E. and May, J.M. (2009) Vitamin C Function in the Brain: Vital Role of the Ascorbate Transporter SVCT2. Free Radical Biology and Medicine, 46, 719-730. http://dx.doi.org/10.1016/j.freeradbiomed.2008.12.018

[11] Birch, L., Savage, J.S. and Ventura, A. (2007) Influences on the Development of Children's Eating Behaviours: From Infancy to Adolescence. Canadian Journal of Dietetic Practice and Research, 68, s1-s56.

[12] Duffey, K.J., Gordon-Larsen, P., Shikany, J.M., Jacobs, D.R. and Popkin, B.M. (2010) Food Price and Diet and Health Outcomes: 20 Years of the CARDIA Study. Archives of Internal Medicine, 170, 420-426. http://dx.doi.org/10.1001/archinternmed.2009.545

[13] Bowman, S.A. and Vinyard, B.T. (2004) Fast Food Consumption of U.S. Adults: Impact on Energy and Nutrient Intakes and Overweight Status. Journal of the American College of Nutrition, 23, 163-168. http://dx.doi.org/10.1080/07315724.2004.10719357

[14] Schroder, H., Covas, M., Elosua, R., Mora, J. and Marrugat, J. (2008) Diet Quality and Life Style Associated with Free Selected Low-Energy Density Diets in a Representative Spanish Population. European Journal of Clinical Nutrition, 62, 1194-1200. http://dx.doi.org/10.1038/sj.ejcn.1602843

[15] ElShaks (1995) Indicators for Assessing the Socioexonomic Status of Households. Anglo Egyptian Press.

[16] Gibson, R. and Fergujson, E. (1999) An Interacting 24 Hour Recall for Assessing the Adequacy of Iron and Zinc Intakes in Developing Countries.1st Edition, Life Sci Inst, Washington DC.

[17] Pennington, J. (1992) Total Diet Studies. The Identification of Core Foods in the United States Food Supply. Food Additives and Contaminants, 9, 253-264. http://dx.doi.org/10.1080/02652039209374069

[18] WHO (2012) GEMS/Food Programme: Report of the WHO Working Group on Collection of Food Consumption Data (COFOCO), 30 January 2012.

[19] Horwitz, W., Ed. (1990) Official Methods of Analysis of the Association of Official Analytical Chemists. 15th Edition, 967.22, 1059-1060, AOAC, USA. 
[20] WHO/FAO (2001) Human Vitamin and Mineral Requirement.

[21] Gibson, R.S. (2005) Principles of Nutritional Assessment. 2nd Edition, Oxford University Press, Dunedin, Chap. 6, 129-149.

[22] Morgan, K.J., Johnson, S.R. and Goumaetas, B. (1987) Analysis of a 12 Day Data Using Persistence Measures. American Journal of Epidemiology, 126, 326-335. http://dx.doi.org/10.1093/aje/126.2.326

[23] De Bourdeaudhuij, I., te Velde, S., Brug, J., Due, P., et al. (2008) Personal, Social and Environmental Predictors of Daily Fruit and Vegetable Intake in 11-Year-Old Children in Nine European Countries. European Journal of Clinical Nutrition, 62, 834-841. http://dx.doi.org/10.1038/sj.ejcn.1602794

[24] Rangan, A.M., Kwan, J.S.L., Louie, J.C.Y., Flood, V.M. and Gill, T.P. (2011) Changes in Core Food Intake among Australian Children between 1995 and 2007. European Journal of Clinical Nutrition, 65, 1201-1210. http://dx.doi.org/10.1038/ejcn.2011.109

[25] Leite, F.M., Ferreira, H.S., Bezerra, M.K., de Assunção, M.L. and Horta, B.L. (2013) Food Intake and Nutritional Status of Preschool from Maroon Communities of the State Alagoas, Brazil. Revista Paulista de Pediatria, 31, 444-451. http://dx.doi.org/10.1590/S0103-05822013000400005

[26] Darmon, N. and Drewnowski, A. (2008) Does Social Class Predict Diet Quality? The American Journal of Clinical Nutrition, 87, 1107-1117.

[27] Kaur, P., Dahiya, S. and Rana, M.K. (2007) Food and Nutrient Intake of Pre-School Children (2-6 Year) of Sonepat District. Journal of Dairying, Foods Home Sciences, 26, 141-146.

[28] Christian, M.S., Evans, C.E.L., Hancock, N., Nykjaer, C. and Cade, J.E. (2012) Family Meals Can Help Children Reach Their 5 A Day: A Cross-Sectional Survey of Children's Dietary Intake from London Primary Schools. Journal of Epidemiology Community Health, 67, 332-338. http://dx.doi.org/10.1136/jech-2012-201604

[29] Keast, D.R., Fulgoni, V.L., Nicklas, T.A. and O’Neil, C.E. (2013) Food Sources of Energy and Nutrients among Children in the United States: National Health and Nutrition Examination Survey 2003-2006. Nutrients, 5, 283-301. http://dx.doi.org/10.3390/nu5010283

[30] Rose, D. and Oliveira, V. (1997) Nutrient Intakes of Individuals from Food-Insufficient Households in the United States. American Journal of Public Health, 87, 1956-1961. http://dx.doi.org/10.2105/AJPH.87.12.1956

[31] Jahns, L., Carriquiry, A., Arab, L., Mroz, T.A. and Popkin, B.M. (2004) Within- and Between-Person Variation in Nutrient Intakes of Russian and U.S. Children Differs by Sex and Age. Journal of Nutrition, 134, 3114-3120.

[32] Arsenault, J.E., Yakes, E.A., Islam, M.M., Hossain, M.B., et al. (2012) Very Low Adequacy of Micronutrient Intakes by Young Children and Women in Rural Bangladesh is Primarily Explained by Low Food Intake and Limited Diversity. Journal of Nutrition, 143, 197-203. http://dx.doi.org/10.3945/jn.112.169524

[33] Faber, M. and Laubscher, R. (2008) Seasonal Availability and Dietary Intake of $\beta$-Carotene-Rich Vegetables and Fruit of 2-Year-Old to 5-Year-Old Children in a Rural South African Setting Growing These Crops at Household Level. International Journal of Food Sciences and Nutrition, 59, 46-60. http://dx.doi.org/10.1080/09637480701664852

[34] Hautvast, J.L.A., van der Heijden, L.J.M., Luneta, A.K., et al. (1999) Food Consumption of Young Stunted and NonStunted Children in Rural Zambia. European Journal of Clinical Nutrition, 53, 50-59. http://dx.doi.org/10.1038/sj.ejcn.1600676

[35] Brion, M.J., Ness, A.R., Smith, G.D., Emmett, P., et al. (2008) Sodium Intake in Infancy and Blood Pressure at 7 Years. Findings from the Avan Longitudinal Study of Parents and Children. European Journal of Clinical Nutrition, 62, 1162-1169. http://dx.doi.org/10.1038/sj.ejcn.1602837

[36] Levine, M., Wang, Y., Padayatty, S.J. and Morrow, J. (2001) A New Recommended Dietary Allowance of Vitamin C for Healthy Young Women. Proceedings of the National Academy of Sciences of the United States of America, 98, 9842-9846. http://dx.doi.org/10.1073/pnas.171318198

[37] Patrick, H. and Nicklas, T.A. (2005) A Review of Family and Social Determinants of Children’s Eating Patterns and Diet Quality. Journal of the American College of Nutrition, 24, 83-92. http://dx.doi.org/10.1080/07315724.2005.10719448 